\title{
ON RAILROAD TANK CAR PUNCTURE PERFORMANCE: PART I - CONSIDERING METRICS
}

\author{
David Y. Jeong \\ Benjamin Perlman \\ Volpe National Transportation Systems Center \\ US Department of Transportation \\ Cambridge, Massachusetts, USA
}

\author{
Karl Alexy \\ Francisco González III \\ Federal Railroad Administration \\ US Department of Transportation \\ Washington, DC, USA
}

\section{ABSTRACT}

This paper is the first in a two-part series on the puncture performance of railroad tank cars carrying hazardous materials in the event of an accident. Various metrics are often mentioned in the open literature to characterize the structural performance of tank cars under accident loading conditions. One of the consequences in terms of structural damage to the tank during accidents is puncture. This two-part series of papers focuses on four metrics to quantify the performance of tank cars against the threat of puncture: (1) speed, (2) force, (3) energy, and (4) conditional probability of release.

In this paper (Part I), generalized tank car impact scenarios are illustrated. Particular focus is given to the generalized shell impact scenario because performance-based requirements for shell puncture resistance are being considered by the regulatory agencies in United States and Canada. Definitions for the four performance metrics are given. Physical and mathematical relationships among these metrics are outlined. Strengths and limitations of these performance metrics are discussed.

In Part II, the multi-disciplinary approach to develop engineering tools to estimate the performance metrics will be described. The complementary connection between testing and modeling will be emphasized. Puncture performance metrics, which were estimated from other sources, will be compared for different tank car designs. These comparisons will be presented to interpret the metrics from a probabilistic point of view. In addition, sensitivity of the metrics to the operational and design factors will be examined qualitatively.

\section{INTRODUCTION}

One of the vulnerabilities that could potentially lead to severe consequences in the event of an accident is puncture of the tank as a result of an object (such as a coupler, wheel, etc.) striking the head or side of the tank. Figure 1 shows an example of head puncture in a railroad tank car. This photograph was taken from an accident that occurred in Casselton, North Dakota on December 30, 2013 [1]. In this case, the railroad tank car, which was carrying crude oil, was not equipped with head shields. Federal regulations were instituted in the 1980s that require head shields to protect railroad tank cars carrying certain classes of hazardous materials [2]. Recently, new regulations have been issued that require head shields for railroad tank cars carrying high-hazard flammable liquids which include crude oil and ethanol [3].

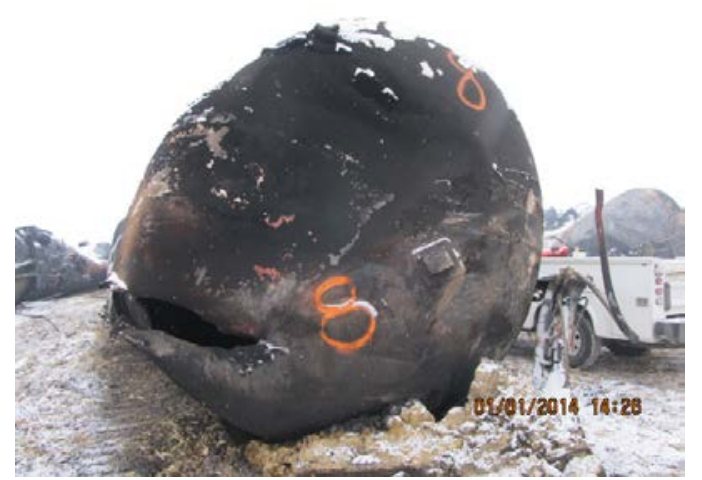

Figure 1: Head Puncture from Casselton Accident 
The sides of a railroad tank car are also vulnerable to puncture. For instance, Figure 2 is a photograph of a side or shell puncture in a railroad tank car that was involved in the train derailment that occurred in Lac-Mégantic, Quebec on July 6, 2013. Forty-two people were confirmed dead, with five more missing and presumed dead, as a result of an unsecured (i.e. runaway) train [4]. This two-part series of papers focuses on side or shell punctures to railroad tank cars in the event of an accident because standards or regulations for side or shell puncture protection do not yet exist.

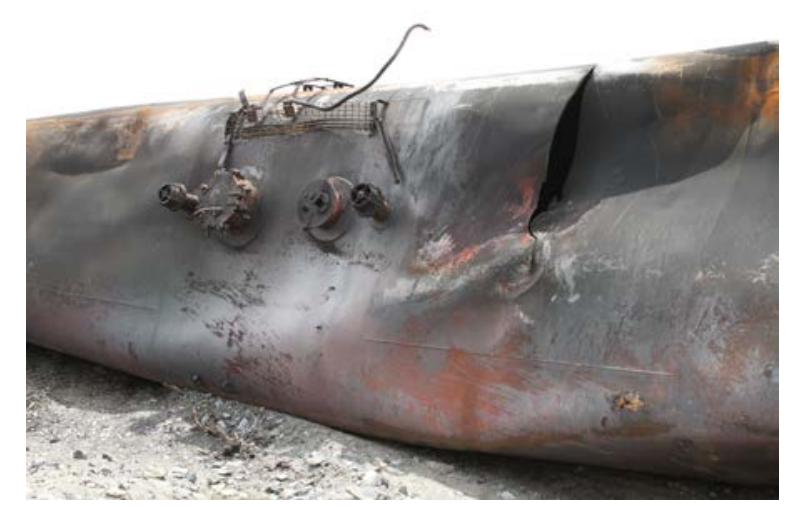

Figure 2: Shell Puncture from Lac-Mégantic Accident

The objectives in this two-part series of papers on tank car puncture performance are: (1) to identify possible performance metrics; (2) to point out the relative strengths and limitations of these metrics; (3) to describe the relationships among the metrics, if any; and (4) to describe the methods used to estimate the metrics. Objectives (1), (2), and (3) are covered in Part I. Part II focuses on objective (4). Moreover, this information is intended to help in the development of rational guidelines to improve the safety performance of railroad tank cars carrying hazardous materials.

\section{GENERALIZED TANK CAR IMPACT SCENARIOS}

Research sponsored by the Government and industry in the 1970s [5] and 1980s [6] led to the development of requirements to equip railroad tank cars with head protection. Figure 3 shows a schematic of the generalized tank car head impact scenario described in the Code of Federal Regulations (CFR), Title 49 §179.16, Specifications for Tank Cars [2]. A moving ram car strikes the head of a subject tank car below the centerline of the head. The ram car must weigh at least 263,000 $\mathrm{lb}$, and strike the subject tank car with a coupler. The impact location on the tank head is specified to be a certain height above the top of the sill. The subject tank car with its brakes released is braced for the impact of the ram car by three fullyloaded backup cars with their brakes applied. Moreover, Appendix A to Part 179 describes a test procedure to verify integrity of tank head puncture resistance systems and to test for system survivability after coupler-to-tank impacts at a relative speed of 18 miles per hour (mph).

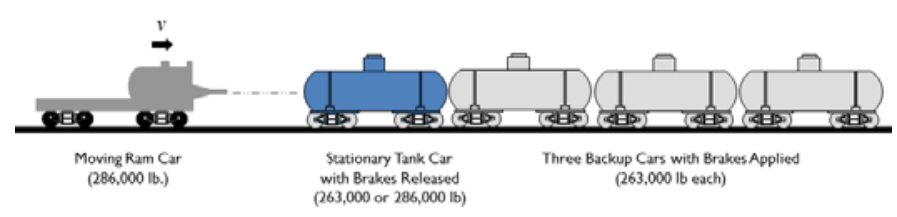

Figure 3: Generalized Head Impact Scenario

Prior to 2007, no research had been conducted to examine the structural integrity and crashworthiness of railroad tank cars under side or shell impacts. Since 2007, a series of full-scale shell impact tests have been performed to examine the structural response of tank cars in the generalized shell impact scenario, which are shown schematically in Figure 4. Moreover, performance-based requirements for shell puncture resistance are being considered by the regulatory agencies in the United States and Canada. A moving ram car strikes the side of a subject tank car at its centerline as it is braced for impact by a rigid barrier. The generalized shell impact scenario shown in Figure 4 was conceived to be an idealized full-scale side impact test that would result in failure modes (such as puncture) similar to those in actual accidents. Among the considerations in the development of the generalized shell impact scenario was that the test be safe, controllable, repeatable, and analyzable. It was also developed to parallel the barrier tests conducted for automobiles.

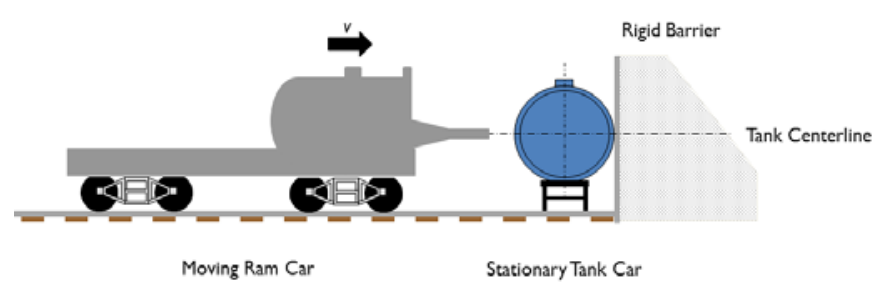

Figure 4: Generalized Shell Impact Scenario

To date, six full-scale tank car shell impact tests have been conducted at the Transportation Technology Center in Pueblo, Colorado, which have been sponsored by the Federal Railroad Administration (FRA). These tests are summarized in Figure 5, which shows: the date on which the test was conducted, the tank car specification, the test impact speed, the indenter size, and whether the test resulted in puncture. The shape of indenter used in these tests was a pyramidal frustum or truncated right pyramid. The impacting surface of the frustum is flat with rounded edges. The height and width of the impacting surface for the indenters used in each test are shown in the legend in the figure. Four tests involved the DOT105 specification tank car, one used a DOT111 car, and one used a DOT112 car. The first three full-scale shell impact tests were conducted under the Next Generation Rail Tank Car Project (NGRTC) [7], which focused on tank cars designed to carry toxic inhalation hazardous materials, specifically chlorine. The fourth test was conducted on a DOT105 car with a curved, 6-foot by 6-foot, 
welded steel sandwich panel to protect the tank from shell puncture [8]. The DOT105 car is a pressure car. Although the DOT112 car is designed and used as a pressure car, it was not pressurized during the conduct of the full-scale test [9] in order to compare its performance relative to the DOT111 car [10], which is not a pressure car. In two of the six tests (one on a DOT105 and the other on the DOT111), puncture of the tank was the desired outcome and was achieved.

\section{METRICS FOR PUNCTURE PERFORMANCE}

What are the metrics which can be used to characterize the performance of railroad tank cars against the threat of puncture from an impacting object in the event of a derailment or collision? In this paper, four metrics are discussed for the generalized shell impact scenario: (1) threshold puncture speed, (2) peak impact force, (3) puncture energy, and (4) probability of lading loss, also known as conditional probability of release (CPR). In the context of these metrics, puncture is defined as any tears, holes, cracks, or perforations in the tank material that would allow the commodity to escape.

\section{Threshold Puncture Speed}

Threshold puncture speed is defined as the highest impact speed at which a railroad tank car can withstand without puncturing. That is, a given object (such as such as a coupler or wheel) striking the head or the side of the tank at an impact speed slightly above the threshold speed is expected to perforate or puncture the tank and release its product. This definition for puncture speed is similar to that for ballistic limit velocity, which is used to measure a target's ability to withstand projectile impact in military applications. Moreover, the desired outcome of puncturing the tank in two of the full-scale impact tests that were shown in Figure 5 was achieved by specifying a test impact speed that was higher than the predicted threshold puncture speed.

\section{Peak Impact Force}

Puncture force is defined in this paper as the force required for an indenter to perforate the commodity-carrying tank. Figure 6 shows a schematic of the force-indentation characteristic for a tank car as it is being struck by an impacting object. The force-indentation characteristic for a given accident scenario (i.e. head puncture or shell puncture) may be derived through testing and/or computational modeling (i.e. finite element analysis).

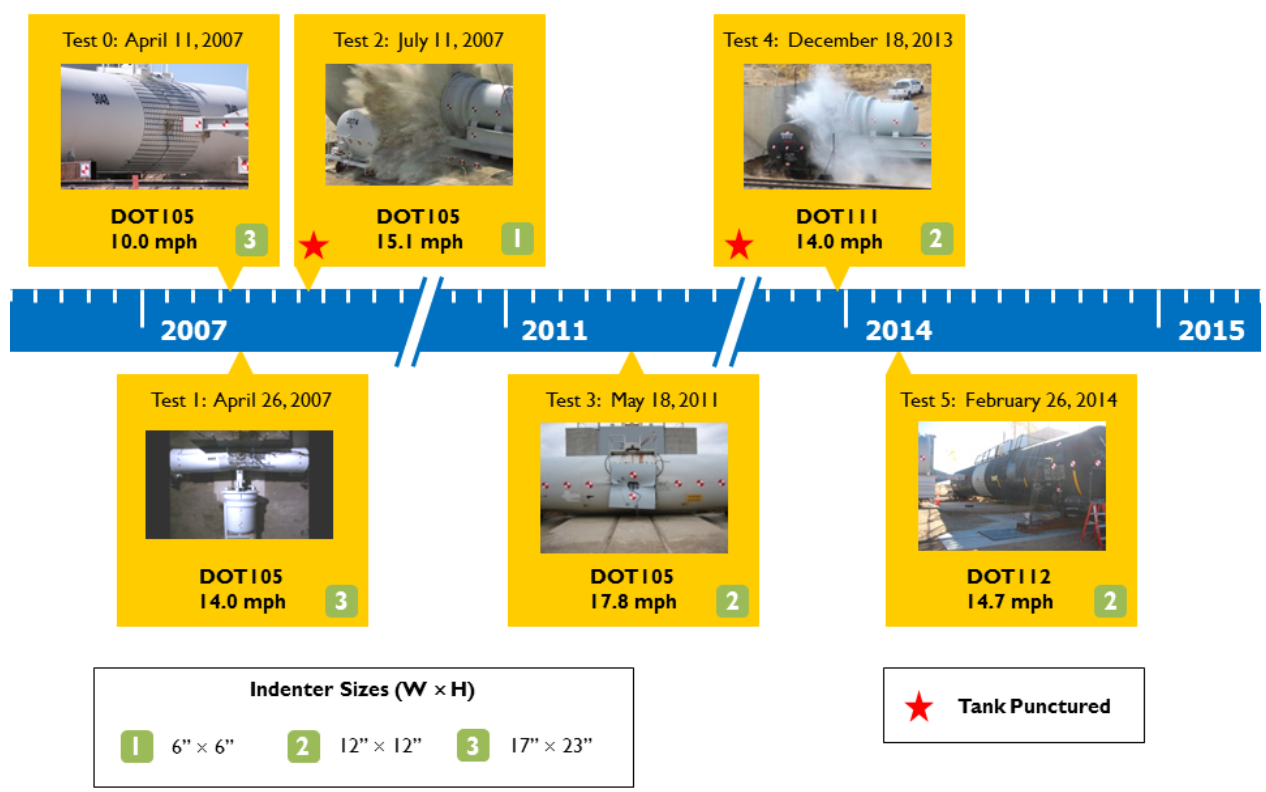

Figure 5: Summary of Full-Scale Tank Car Shell Impact Tests 


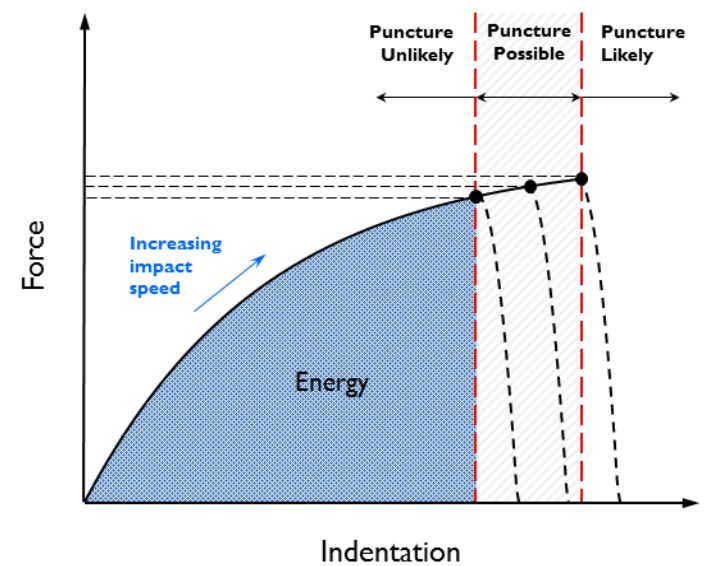

Figure 6: Generic Force-Indentation Characteristic

The specific point at which puncture occurs along the force-indentation characteristic depends on several factors such as size, shape, and initial speed of the indenter. The force at which the indenter initially pierces the tank may actually occur prior to the peak force. Since the peak force is a distinct and readily discernible point on the force-indentation characteristic, the peak force and the puncture force are assumed to be coincident in this paper.

It is implied in Figure 6 that higher peak impact forces will occur as the impact speed increases. The schematic also shows three regions where puncture of the tank is unlikely, possible, and most likely to occur. The region in which puncture is possible may be considered as representing the uncertainties and variabilities in estimating puncture. With such considerations in mind, it may be prudent to view puncture performance probabilistically.

In theory, puncture speed and the peak impact force are related through the principle of impulse-momentum. Impulse is calculated by integrating the force-time history over the duration of the impact event. In order to calculate the change in momentum, the initial and final impact speeds must be known.

\section{Puncture Energy}

Referring to the schematic in Figure 6, energy is represented by the area under the force-indentation curve or characteristic. In theory, speed and energy are related through kinetic energy. Based on the physics principles of energy conservation and impulse-momentum, puncture energy and kinetic energy are identically equal if the final momentum, and therefore final impact speed, of the ram car is equal to zero. That is, the two energies are equal to each other if the ram car comes to a complete stop at the same time when puncture of the tank occurs.

Figure 7 compares the force-displacement calculations from finite element analyses with data obtained from full-scale testing on a DOT111 tank car. The rapid drop-off in the impact force after the peak characterizes puncture of the tank. The test impact speed was $14 \mathrm{mph}$ and the ram car weight was 297,125 $\mathrm{lb}$, which corresponds to 1.95 million $\mathrm{ft}-\mathrm{lb}$ of kinetic energy. The dimensions of the indenter footprint were 12 inches by 12 inches. The area under the force-displacement curve from the test data is calculated to be 1.45 million $\mathrm{ft}-\mathrm{lb}$. The energy corresponding to the area under the FEA force-displacement curve is 1.49 million $\mathrm{ft}-\mathrm{lb}$, which is within 3 percent of the test result. Moreover, the force-displacement characteristic from the numerical analysis shows excellent agreement with the test.

The area under the force-displacement characteristic from the test is 1.45 million $\mathrm{ft}-\mathrm{lb}$. The residual energy (or difference between the kinetic energy of 1.95 million $\mathrm{ft}-\mathrm{lb}$ and the area under the curve from the test) is 0.5 million $\mathrm{ft}-\mathrm{lb}$, which is more than 25 percent of the original kinetic energy. Clearly, the test impact speed of $14 \mathrm{mph}$ is greater than the threshold puncture speed. An impact speed corresponding to the area under the curve from the test is back-calculated to be $12.1 \mathrm{mph}$ for the ram car used in the test. The accuracy of this impact speed as an estimate of the threshold puncture speed is uncertain without additional testing and/or analysis because the impact behavior of the tank in the generalized shell impact scenario is nonlinear with respect to material failure.

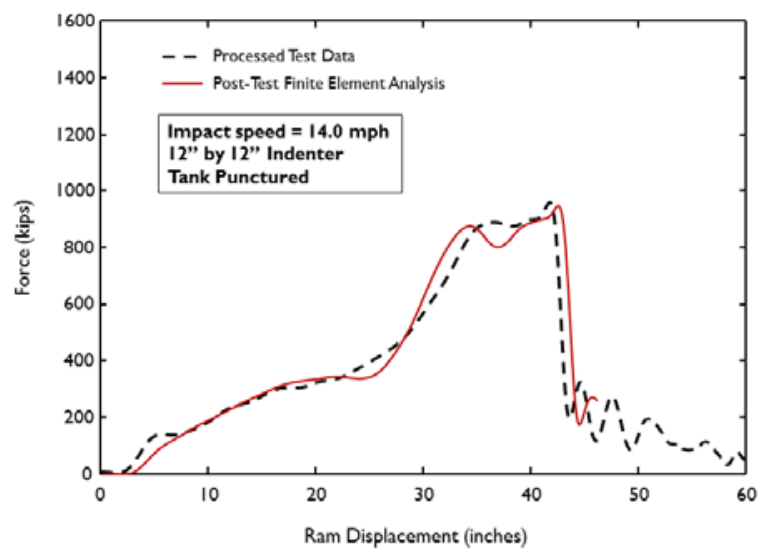

Figure 7: Comparison between Full-Scale Test and Finite Element Analysis for DOT111

Similarly, Figure 8 compares finite element analysis (FEA) results with the test data for the DOT112. The impact speed of $14.7 \mathrm{mph}$ with the ram car weight of $297,125 \mathrm{lb}$ corresponds to 2.1 million $\mathrm{ft}-\mathrm{lb}$ of kinetic energy. In this test, however, the integrity of the tank was maintained. The test data indicates that the tank reached a maximum indentation of about 52 inches and a peak impact force of approximately 1.1 million lb without resulting in puncture. This full-scale test demonstrates that the DOT112 specification tank car can withstand an impact speed of at least $14.7 \mathrm{mph}$ under the generalized shell impact conditions without loss of lading. The force-displacement curve calculated from the FEA for this case also closely follows the test data up to the peak force. Since the tank did not puncture in the full-scale test, additional numerical analyses must be conducted to estimate the threshold puncture speed, force, and energy. 


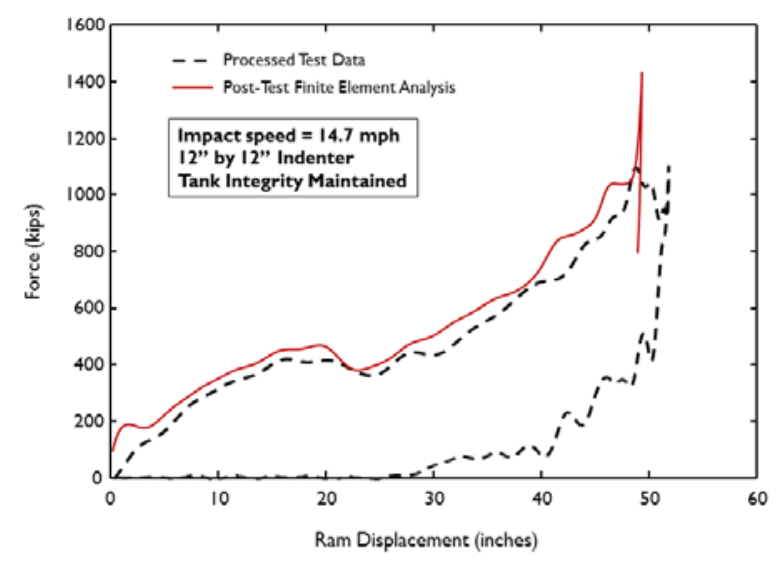

Figure 8: Comparison between Full-Scale Test and Finite Element Analysis for DOT112

Table 1 lists the general characteristics of the DOT111 and the DOT112 tank cars that were used in the full-scale shell impact testing. The difference in the puncture behavior between these two cars is attributed to the differences in shell thicknesses and grades of steel.

Table 1: Characteristics of DOT111 and DOT112

\begin{tabular}{lll}
\hline & DOTI I I I OOW & DOTI I 2J340W \\
\hline Shell Thickness & $7 / 16$ inch & 0.618 inch \\
Head Thickness & $7 / 16$ inch & $11 / 16$ inch \\
& ASTM 515, Grade 70 & $\begin{array}{l}\text { TCI } 28, \text { Grade B, } \\
\text { Normalized } \\
\text { Steel }\end{array}$ \\
Tank Diameter & $\begin{array}{l}\text { Sloping bottom rings; } 106 \\
\text { to } 1101 / 4 \text { inches }\end{array}$ \\
Insulation & 4 inches & $1 / 2$ inch \\
& & \\
\hline
\end{tabular}

\section{Conditional Probability of Release}

Conditional probability of release (CPR) is the probability that release of hazardous material (hazmat) will occur given that an accident has already occurred. CPR is a numerical value that is calculated in quantitative evaluation of risk. For example, Figure 9, which was extracted from Reference [11], shows the chain of events starting from the occurrence of a train accident through a series of steps leading to the release of hazmat. The chain of events was also used in previous studies to estimate the risk associated with the transportation of hazardous materials by rail [12]. CPR is calculated in Step 4 of the schematic diagram as the fraction or percentage of hazmat cars that release some or all of their lading.

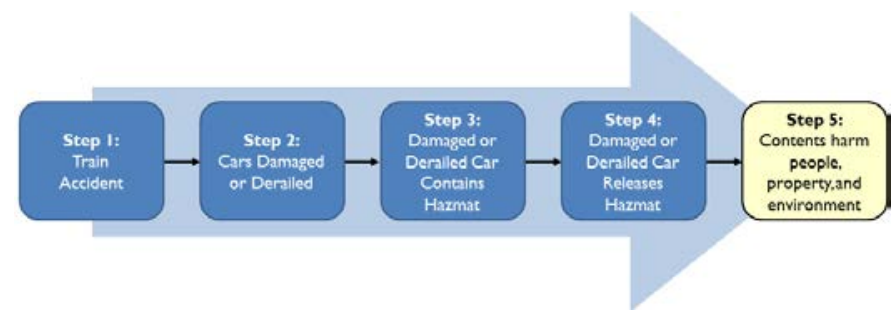

Figure 9: Chain of Events Leading to Tank Car Hazardous Materials Release [11]

Treichel et al. [13] applied logistic regression analysis to estimate CPR using data from the Tank Car Accident Damage database. The database is maintained by the Railroad Tank Car Safety Research and Test Project, which is sponsored by the Railway Supply Institute (RSI) and the Association of American Railroads (AAR). The term "logistic" refers to the functional form of the mathematical equations used to characterize the effect of different factors on the probability of lading loss. "Regression" means that the mathematical equations were curve-fit to represent the data. Moreover, lading loss is assumed to occur from four specific sources: (1) head releases, (2) shell release, (3) releases from top fittings, and (4) releases from bottom fittings. The logistic regression assumes that the most significant factors contributing to the probability of lading loss from each source are: (a) whether a head shield is present and if so what type, (b) thickness of the head, (c) whether the tank is jacketed or not, (d) whether double-shelf couplers are present, (e) thickness of the shell, (f) whether the car is pressurized or not, and (g) if the accident occurred in a yard or on mainline track. Further details of the regression analysis and the trends for conditional probability of release are described in Treichel et al. [13].

Figure 10 shows the conditional probability of release for shell losses as reported in Treichel et al. [13] for mainline accidents. The figure shows two sets of results; one for nonjacketed cars and another for jacketed cars. Lower values of CPR correspond to improved resistance to puncture. The figure clearly shows the benefit of incorporating a jacket in the tank car design to improve puncture resistance. The figure also shows that the two curves are descending, and appear to be converging as shell thickness becomes greater, indicating a diminishing benefit for improved puncture resistance as the tank shell becomes thicker. The error bars and shaded areas for each set of results represent the $95 \%$ confidence interval, which is calculated in accordance with Appendix B in Reference [13]. 


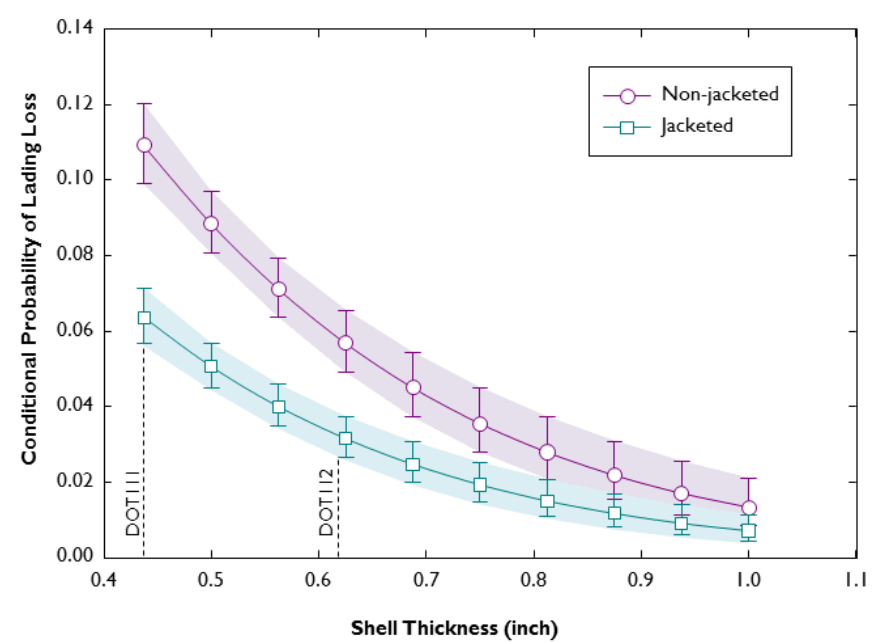

Figure 10: Conditional Probability of Release for Shell Losses with 95\% Confidence Intervals

CPR values for the DOT111 and DOT112 cars that were used in the full-scale shell impact tests can be estimated from Figure 10 using the shell thicknesses listed in Table 1. Both of these cars were jacketed. The lower and upper bound values of CPR values for the DOT111 car are 0.057 and 0.071 , with a mean value of 0.064 . Those for the DOT112 car are 0.027 and 0.038 with a mean or average value of 0.032 . These comparative estimates for CPR provide a means to quantify the improvement in puncture performance by increasing shell thickness (and by jacketing the car). However, the absolute value of CPR (or the associated range within the 95\% confidence band) applies only within the context of accident history, and may not be appropriate to future events. In other words, a prediction on the puncture performance of a new innovation design for tank cars based on CPR may be inaccurate because the accident performance history for that design has not yet been established.

In Part II of this two-part series of papers, numerical studies are conducted to compare the puncture performance metrics described in this paper (i.e. threshold puncture speed, peak impact force, puncture energy, and conditional probability of release) for different tank car designs

\section{DISCUSSION}

Figure 6 (generic force-indentation characteristic) and Figure 10 (conditional probability of release for shell losses) exhibit a common feature. The schematic of the forceindentation curve includes a cross-hatched area representing a zone in which puncture is possible, and the CPR curves include shaded areas representing the $95 \%$ confidence interval. In both figures, the shaded areas indicate that the numerical value associated with that particular metric is not a precise and absolute number. Moreover, these illustrations suggest that these performance metrics are probabilistic.
The generalized shell impact scenario is not intended to reconstruct or reenact any specific accident, such as Casselton or Lac-Mégantic, but it is intended to replicate essential characteristics observed in accidents, such as plastic deformation and possible puncture of the tank. Moreover, the full-scale test is idealized to provide a means to compare alternative tank car designs while being amenable to computational analysis. (The role of finite element analysis in estimating puncture performance metrics will be discussed in Part II.) The test is considered to be relatively safe and controlled because the tank is braced against a concrete wall during impact. However, by restricting its movement in the direction of impact, the structural demand on the tank is severe.

How does the impact speed in the generalized impact scenario relate to impact speeds in actual accidents? Studies on derailment dynamics have been conducted to estimate car-to-car collision speeds as a result of a derailment [14]. A planar model was developed to examine the gross motions of rail cars in a generalized derailment. The two-dimensional model is representative of flat terrain and straight (i.e. tangent) track. Sensitivity analyses were performed using the derailment dynamics model by varying factors such as train speed, angular velocity (to initiate the derailment scenario), train length (i.e. number of cars in the train consist), car mass, ground friction, and rail friction. These analyses indicated that train speed was the most important variable in terms of derailment severity (number of cars derailed, relative velocities between impacting cars, and impact forces). Other factors such as coupler swing angle and criteria for breaking couplers and uncoupling also play a role in the derailment dynamics, but their relative sensitivities were not studied in detail. One of the results from the derailment dynamics studies was the so-called rule-ofthumb, which is stated verbatim here: "For example, the closing velocities in post-derailment car-to-car impacts appear to average about half of the initial train speed.” Further review of these results indicates that the standard deviation on the closing speeds in post-derailment car-to-car impacts is on the order of $3 \mathrm{mph}$ based on the range of assumed values in the sensitivity analysis.

CPR has been used as a puncture performance because its value is readily calculated in any formal risk analysis. For example, the chain of events shown schematically in Figure 9 establishes a framework to relate CPR to safety consequences. However, it is difficult to envision how a numerical value of CPR can be directly confirmed or refuted through a single test.

Furthermore, the relationship between puncture energy or speed and conditional probability of lading loss is not selfevident. These relationships have been explored using Monte Carlo and probabilistic methods [15]. The probabilistic sensitivity analysis in [15] indicates that the size of the indenter or impactor plays a significant role in establishing any relationship between speed and CPR. Unfortunately indenter size is often not reported or unknown in accident reports and data. 
The key to CPR is comprehensive accident data. However, the RSI-AAR Tank Car Accident Damage Database is the only source of data available to analyze the dependence of CPR on tank car design factors such as head and shell thickness, valves and fittings, head shields and jackets, and shelf couplers. The logistic regression analysis described in [13] accounts for these factors as well as others (such as internal pressurization, mainline versus yard accidents, etc.), but other variables that have an effect on the tank car's resistance to damage were not considered (such as indenter size and outage, which might not be known for a given accident). In addition, the regression analysis is based on accident data from 1965 to 1995. Systemic variation in CPR exists because material requirements (e.g. normalized steel) and manufacturing processes have evolved over this same period of time. Developments and requirements for tank car safety features have also advanced over time.

Estimates of CPR may be subject to considerable uncertainty especially when it used to forecast trends in future accidents. The uncertainty reduces the confidence in estimating and extrapolating values of CPR, especially for tank cars with higher thicknesses in which the accident data may contain relatively few observations of releases. Moreover, the railroad operating environment is constantly evolving over time. For example, axle loads and trains speeds are tending to increase.

Figure 11 shows a plot of the number of derailed cars and the estimated train speed at the time of derailment for 20 accidents that have occurred since 2006 in North America. Seven of these accidents involved the release of ethanol; the other thirteen (13) accidents involved the release of crude oil. Information on these accidents was obtained from the FRA Factual Railroad Reports (Form FRA F 6180.39) and accident investigation reports published by the National Transportation Safety Board. The figure also shows a regression curve derived by Barkan et al. [16] based on FRA accident data for 839 mainline freight derailments in which at least one hazmat car was damaged or derailed over the period between 1992 and 2001. The error bars associated with the lower regression curve are \pm two standard errors from the mean. In all seven of the ethanol-related accidents, the number of derailed cars is greater than the Barkan et al. regression curve. In all but three of the accidents involving crude oil, the number of derailed cars is greater than the Barkan et al. regression curve.

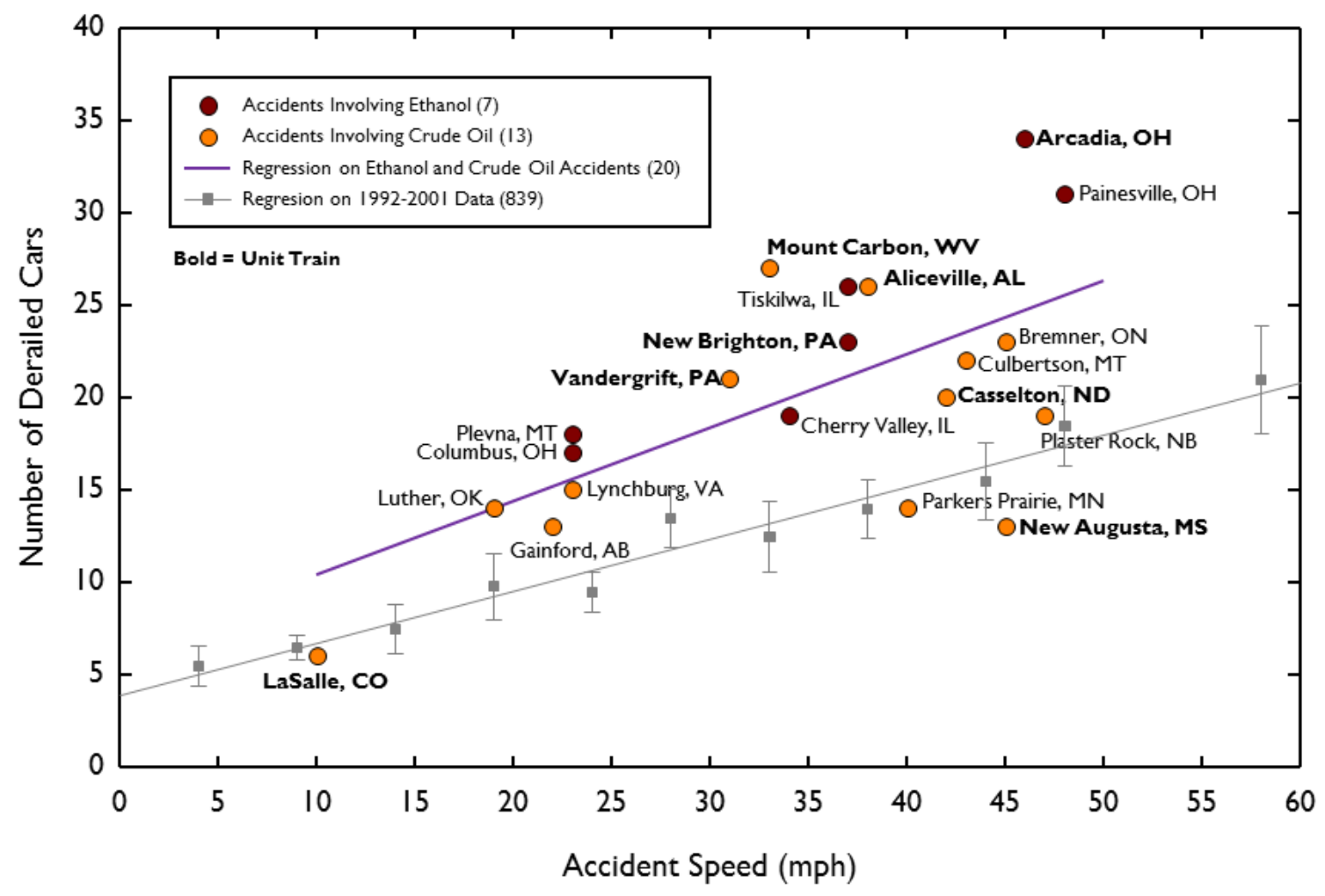

Figure 11: Relationship between Accident Speed and Number of Derailed Cars 
Although the sample size for accidents involving ethanol and crude oil is small, the discrepancy between the regression curve for the 20 accidents since 2006 and the Barkan et al. regression analysis begs the question: why is there such a difference? One possible answer is that unit (i.e. singlecommodity) trains are more common now than in the past, especially since the timeframe over which the Barkan regression analysis is based. The figure also identifies eight accidents with bold font that involved unit trains transporting high-hazard flammable liquids (i.e. crude oil and ethanol). In addition, average train lengths appear to be on an increasing trend. The average train length in the data examined by Barkan et al. is on the order of 80 cars. The data for the more recent accidents involving ethanol and crude oil is incomplete at this time. Based on the available information, the total number of cars in the train consist exceeds 80 cars in all of the accidents in which information is available except for one. The exception is Arcadia, Ohio with a total of 62 cars; 34 of which derailed, 33 of the derailed cars were hazmat cars, and all 33 hazmat cars released ethanol. However, the data point on the figure corresponding to Arcadia is the furthest from the Barkan et al. regression curve. Figure 11 does not include the Lac-Mégantic accident in which 63 cars derailed at an estimated speed of 65 mph [4]. If the Lac-Mégantic accident is included the regression analysis for crude oil and ethanol releases, the trend line would be skewed even farther from the Barkan et al. curve.

\section{CONCLUDING REMARKS}

Four different metrics are considered in this paper to characterize the structural performance of railroad tank cars under a generalized shell impact which might lead to puncture: (1) speed, (2) force (3) energy, and (4) probability of lading loss, also known as conditional probability of release (CPR).

Speed, force, and energy are related through physics, specifically via the mechanics principles of energy conservation and impulse-momentum. However, these three metrics, whether they are determined from testing or modeling, apply only to a given set of fixed parameters under the generalized shell impact scenario. These fixed parameters include: tank car design or specification, indenter size and shape, commodity type, internal pressure, outage, top and bottom fittings, and safety features (such as pressure relief valves, head shields, double-shelf couplers, and thermal protection). A separate test and/or analysis must be performed to determine the performance metric if any of these parameters are varied.

Current regulations describe a test procedure to verify the integrity of tank head puncture resistance systems [2]. Compliance is demonstrated if the tank survives a certain impact speed under the prescribed test conditions. That is, speed is specified in the current regulations as a puncture performance metric.

Conditional probability of release (CPR) provides a link to accident history, which can be used to help validate modeling efforts. However, extrapolations using CPR as a performance metric must be heeded with caution. For example, prediction of puncture performance of new and innovative tank car designs based on CPR may be fraught with uncertainty because an accident history has not yet been established. Moreover, CPR assumes that past accidents are representative of future accidents.

In Part II of this two-part series, the methodologies and disciplines used to develop engineering tools to estimate the performance metrics are reviewed. The complementary roles of physical testing and modeling are emphasized as essential elements in the overall process. That is, convergence of results from physical testing and computational modeling provides confidence and credibility in the ability to estimate these performance metrics. Part II also includes numerical experiments or studies to compare performance metrics that have been estimated from previous work for different railroad tank cars under the generalized side or shell impact scenario. Moreover, the estimates of these metrics to quantify puncture performance are interpreted from a probabilistic point of view.

\section{ACKNOWLEDGMENTS}

The work described in this paper was sponsored by the Federal Railroad Administration (FRA), Office of Research and Development. Mr. Kevin Kesler is the Chief of the Equipment and Operating Practices Division. Dr. John Tunna is the Director of Research and Development.

The authors would like to thank and acknowledge Mr. Paul Stancil, Senior Hazmat Accident Investigator for the National Transportation Safety Board, for providing the photographs of the head and shell punctures.

The authors would also like to thank Mr. Michael Carolan, Senior Engineer at the Volpe National Transportation Systems Center, for providing his comments and suggestions during the writing of this paper.

\section{REFERENCES}

1. National Transportation Safety Board (NTSB) Forum on Crude Oil and Ethanol by Rail

http://www.ntsb.gov/news/events/2014/railsafetyforum/pres entations/Opening\%20Presentation\%20Rail\%20Accidents \%20Involving\%20Crude\%20Oil\%20and\%20Ethanol\%20R eleases.pdf

2. Code of Federal Regulations, Title 49 - Transportation, Appendix A to Part 179 - Procedures for Tank-Head Puncture-Resistance Test, Pipeline and Hazardous Materials Safety Administration, January 2015.

3. Pipeline and Hazardous Materials Safety Administration, "Hazardous Materials: Enhanced Tank Car Standards and Operational Controls for High Hazard Flammable Trains," PHMSA-2012-0082, May 2015

https://www.fra.dot.gov/Elib/Document/14508

4. Transportation Safety Board of Canada, Railway Investigation R13D0054 
http://www.tsb.gc.ca/eng/enquetesinvestigations/rail/2013/r13d0054/r13d0054.asp

5. Phillips, E.A., and Olsen, L., "Final Phase 05 Report on Tank Car Head Study,” RPI-AAR Tank Car Safety Research and Test Project, Report RA-05-17, 1972.

6. Coltman, M., and Hazel, M., "Chlorine Tank Car Puncture Resistance Evaluation,” Final Report DOT/FRA/ORD92/11, June 1992. http://ntlsearch.bts.gov/tris/record/ntl/34542.html

7. Tyrell, D.C., et al., "Improved tank car safety research," Proceedings of the 2007 ASME Rail Transportation Division Fall Technical Conference, RTDF2007-46013, September 2007.

http://ntlsearch.bts.gov/tris/record/ntl/47516.html

8. Carolan, M.E., et al., "Application of Welded Steel Sandwich Panels for Tank Car Shell Impact Protection,” Final Report DOT/FRA/ORD-13/19, April 2013. http://ntlsearch.bts.gov/tris/record/ntl/47437.html

9. Rakoczy, P., and Carolan, M., "Side Impact Test and Analysis of a DOT112 Tank Car," Final Report in Preparation.

10. Kirkpatrick, S.W., et al., "Side Impact Test and Analysis of a DOT-111 Tank Car," Final Report DOT/FRA/ORD15/30, October 2015.

https://www.fra.dot.gov/eLib/Details/L17092

11. Bing, A., et al., "Risk Evaluation Framework and Selected Metrics for Tank Cars Carrying Hazardous Materials,” Final Report, DOT/FRA/ORD-15/07, May 2015.
https://www.fra.dot.gov/eLib/details/L16361\#p1_z5_gD_lR T_y2015_m5

12. Nayak, P.R., Rosenfield, D.B., and Hagopian, J.H., "Event Probabilities and Impact Zones for Hazardous Materials Accidents on Railroads," Final Report DOT/FRA/ORD83/20, November 1983.

http://ntlsearch.bts.gov/tris/record/ntl/33356.html

13. Treichel, T.T., et al., "Safety Performance of Tank Cars in Accidents: Probabilities of Lading Loss,” RSI-AAR Tank Car Safety Research and Test Project Report RA 05-02, January 2006.

14. Jeong, D.Y., et al., "Equations of Motion for Train Derailment Dynamics," Proceedings of the 2007 ASME Rail Transportation Division Fall Technical Conference, RTDF2007-46009, September 2007. http://ntlsearch.bts.gov/tris/record/ntl/47514.html

15. Jeong, D.Y., "Probabilistic Approach to Conditional Probability of Release of Hazardous Materials from Railroad Tank Cars during Accidents," Proceedings of the 2009 ASME International Mechanical Engineering Congress and Exposition, IMECE2009-10872, November 2009. http://ntlsearch.bts.gov/tris/record/ntl/43027.html

16. Barkan, C.P.L., Dick, C.T., and Anderson, R., "Railroad Derailment Factors Affecting Hazardous Materials Transportation Risk," Transportation Research Record 1825, Paper No. 03-4429, 2003.

http://railtec.illinois.edu/cee/pdf/Barkan_et_al_2003.pdf 